\title{
Memória de trabalho: uma proposta de avaliação infantil
}

\author{
Working memory: a proposal for child evaluating
}

\author{
Mayra Monteiro Pires \\ Universidade Estadual de São Paulo - USP - São Paulo - São Paulo - Brasil
}

\section{Gustavo Lopez Estivalet}

Université Claude Bernard Lyon 1 - UCBL - Lião - França

\begin{abstract}
Resumo:A memória de trabalho consiste em um sistema de capacidade limitada que permite o armazenamento temporário e a manipulação desta informação para habilidades complexas como a linguagem, a aprendizagem e o raciocínio. A presente pesquisa tem como objetivo apresentar a construção, a adaptação e a avaliação de quatro testes psicolinguísticos de memória de trabalho para o português brasileiro, baseados na bateria de testes inglês Memory Test Battery For Children. Os testes adaptados foram aplicados em uma investigação piloto em um grupo experimental de 15 crianças com dificuldades escolares comparados a um grupo controle de 15 crianças com desenvolvimento normal. A adaptação dos testes foi desenvolvida no programa E-Prime v 2.0 Professional®. Os quatro testes psicolinguísticos avaliam a capacidade de armazenagem e processamento da informação de forma simultânea, assim como a capacidade de armazenagem especifica da informação verbal. Os resultados sugerem que os quatro testes desenvolvidos para o português são instrumentos sensíveis para detectar dificuldades no sistema de memória de trabalho em crianças, pois o desempenho entre os dois grupos foi significativamente diferente de acordo com os resultados da análise estatística. A bateria de testes desenvolvidos atendeu os objetivos propostos de avaliação, podendo contribuir com estudos futuros por meio de dados mais concretos com número maior de sujeitos e evidenciar o desenvolvimento da memória de trabalho em crianças.
\end{abstract}

Palavras-chave:Memória de trabalho. Aprendizagem. Psicolinguística. Aquisição da linguagem.

\begin{abstract}
The working memory is a system with limited capacity which allows the temporary storage and manipulation of information to cognitive complex abilities like language, learning and reasoning. This study has as the objective present the construction, the adaptation and the evaluation of four psycholinguistics working memory tests in Brazilian Portuguese that were based in the English battery of tests Memory Test Battery For Children. The tests adapted were applied in a pilot investigation in a group of 15 children with learning school difficulties and compared to a group of 15 children with normal development. The adaptation of the tests was developed in the E-Prime v2.0 Professional ${ }^{\circledR}$ software. The four psycholinguistic tests access the simultaneous storage and processing capacities of information in general domain, as also specific for language information. The results suggest that the four tests are sensible instruments to detect possible difficulties in the working memory processing in children, because they could identify the different performances between the two groups in a statistical analysis. The tests developed perfectly attended their aims for evaluation and can contribute in a near future for other studies with a greater number of subjects, providing a more concrete and evidences of working memory development in children.
\end{abstract}

Keywords: Working Memory. Learning.Psycholinguistics. LanguageAcquisition. 


\section{Introdução}

O sistema de memória de trabalho refere-se a uma capacidade limitada que permite 0 armazenamento temporário e a manipulação de informação para habilidades cognitivas complexas como a linguagem, a aprendizagem e o raciocínio (ALLOWAY; GATHERCOLE; ADAMS; WILLIS, 2005). Alguns estudos relacionam 0 processamento da linguagem com o sistema de memória de trabalho e apontam que esse tipo de memória exerce um papel decisivo nas operações linguísticas, como por exemplo, a aprendizagem de novas palavras e/ou a compreensão da linguagem (BADDELEY; HITCH, 1974). Para a compreensão do significado de uma sentença, um indivíduo deve ser capaz de lembrar as palavras prévias na respectiva ordem em que foram apresentadas (RODRIGUES, 2001). Durante esse processo, a memória de trabalho deve armazenar a compreensão parcial da sentença e codificar os itens para posteriormente realizar a sua recuperação (GATHERCOLE; ALLOWAY; WILLIS; ADAMS, 2006).

A memória de trabalho também é um sistema importante para as habilidades cognitivas envolvidas nos processos de alfabetização e de aprendizagem em geral. A codificação fonológica na memória de trabalho desempenha um papel fundamental na decodificação de novas palavras, principalmente das palavras mais longas que são decodificadas por partes (GINDRI; KESKE-SOARES; MOTA, 2007). A capacidade de segmentar fonemas requer o auxílio da memória de trabalho para a manutenção de informação no sistema de armazenamento, enquanto os fonemas são segmentados e distribuídos em sequência. Partindo desse ponto de vista, a memória de trabalho é fundamental para os processos de aprendizagem da correspondência grafema-fonema (PINHEIRO, 1994). Outros estudos também têm apontado uma forte relação entre a memória de trabalho e as habilidades de leitura (SWANSON; JERMAN, 2007). Para a compreensão de um texto, o leitor necessita armazenar e decodificar o que leu recentemente enquanto realiza procedimentos complexos relacionados à construção do significado
(DE BENI; BORELLA; CARRETI, 2007). A memória de trabalho também está relacionada a testes que avaliam a consciência fonológica, já que a retenção da informação é essencial para a compreensão de orações faladas e escritas, assim como para a manipulação dos elementos que constituem as palavras (SANTOS; SIQUEIRA, 2002).

O modelo de representação mental do sistema de memória de trabalho foi proposto inicialmente por pesquisadores que buscavam explicar 0 processamento da memória de curto prazo em habilidades cognitivas. Tal modelo apresenta um componente denominado executivo central, que por sua vez realiza o controle da atenção, sendo capaz de gerenciar simultaneamente $o$ armazenamento e o processamento de informações de curto prazo (BADDELEY; HITCH, 1974). O executivo central supervisiona e coordena três sistemas escravos: a alça fonológica, responsável pela manipulação da informação baseada na informação verbal, o componente visual-espacial, responsável pelo armazenamento de imagens visuais e localização espacial e o buffer episódico, que ressalta o papel da memória de longo prazo sobre a memória de trabalho (BADDELEY, 2000).

Com base neste modelo inicial de representação mental da memória de trabalho, Pickering e Gathercole (2001) propuseram a bateria de testes de memória em inglês Memory Test Battery For Children. Essa bateria de testes foi baseada em 25 anos de pesquisas realizadas com memória de trabalho em mais de 750 crianças anglófonas, sendo considerada um instrumento preciso e poderoso capaz de detectar dificuldades relacionadas aos componentes e características da memória de trabalho. Os testes da bateria original em inglês contém subtestes designados a acessar os componentes específicos de memória de trabalho e atribuem avaliação aos principais componentes do modelo: a) o executivo central, b) a alça fonológica, ambos com estímulos linguísticos e não linguísticos e c) o componente visual-espacial, apenas com estímulos não linguísticos. As autoras sugerem que a Memory Test Battery For Children pode ser utilizada a 
partir dos oito anos de idade em crianças normais e com dificuldades escolares (PICKERING; GATHERCOLE, 2001).

Devido à existência de poucos instrumentos automatizados em programas disponíveis no português brasileiro, que sejam apropriados para crianças e que avaliem o sistema de memória de trabalho com a especificidade de cada um de seus componentes, realizamos a adaptação de quatro testes para o português brasileiro com base na Memory Test Battery For Children com estímulos linguísticos, que por sua vez passa a se chamar Bateria de testes de memoria de trabalho para crianças (BTMTC).

\section{Metodologia}

Para a adaptação dos quatro testes que avaliam o sistema de memória de trabalho e a aplicação de tais testes em um estudo piloto, o presente estudo teve aprovação do comitê de ética da Universidade Federal de Santa Catarina (UFSC) sob o número 02077612.4.0000.0121 e teve a assinatura dos responsáveis das crianças participantes no Termo de Consentimento Livre e Esclarecido.

Os testes de memória de trabalho que serão descritos na próxima seção foram aplicados em crianças de nove a dez anos que participaram de um projeto promovido pelo curso de Fonoaudiologia da UFSC que teve como objetivo detectar dificuldades relacionadas à aprendizagem escolar. Para esse estudo, tivemos a participação de dois grupos de crianças, um grupo controle constituído de 15 crianças com desenvolvimento normal, sendo oito do sexo feminino e sete do sexo masculino, na faixa etária de nove e dez anos, e um grupo experimental constituído de 15 crianças com dificuldades escolares e com ausência de diagnóstico de alterações neurológicas, sendo nove do sexo feminino e seis do sexo masculino. Para caracterizar os dois grupos, utilizamos como material de base os Testes de Recepção e Produção da Linguagem Oral (SCLIARCABRAL, 2003b), a bateria de testes que avalia a consciência fonológica CONFIAS (MOOJEN et al.,
2011) e os testes formais que avaliam o processamento auditivo, sendo eles: a) o Teste Dicótico de Dígitos (SANTOS; PEREIRA, 1997), o Pediatric Speech Inteligibility (PSI) com sentenças (ZILLIOTTO; KALIL; ALMEIDA, 1997), o teste Gaps in Noise (GIN) (MUSIEK et al. 2005). Todas as crianças do grupo experimental apresentaram desempenho inferior na avaliação da consciência fonológica, leitura e escrita e processamento auditivo quando comparadas ao grupo controle em todas as avaliações segundo os resultados dos padrões de normalidade para cada avaliação e análise estatística, estabelecendo de forma coerente e confiável os dois grupos da amostra.

Os quatro testes que avaliam o sistema de memória de trabalho foram elaboradas no Laboratório de Linguagem e Processos Cognitivos - LabLing, situado no Centro de Comunicação e Expressão CCE da UFSC. Foram necessários cerca de três meses para a construção dos testes para em seguida aplicá-los no estudo piloto. Todos os estímulos de áudio utilizados no presente trabalho foram gravados com uma voz feminina em ambiente silencioso, com um microfone da marca Essence. As gravações foram editadas no programa Audacity 2.0.

Conforme já descrito anteriormente, os quatro testes adaptados para o português brasileiro, formando a Bateria de Testes de Memória de Trabalho para Crianças (BTMTC) foram baseados na bateria de testes em inglês Memory Test Battery For Children. Todos os testes foram adaptados e construídos no programa E-Prime v2.0 Professional® (SCHNEIDER; ESCHMAN; ZUCCOLOTTO, 2007), que consiste em um programa desenvolvido especialmente para a criação e aplicação de testes psicológicos e cognitivos. Depois de finalizados, os testes foram apresentados e realizados em um computador da marca Samsung, modelo Notebook 305E4A-BD1, com tela de 14 polegadas e com as caixas de som da marca Philips.

Todos os testes descritos, a seguir, apresentaram uma primeira fase de aprendizagem, com as instruções e a descrição do teste, uma segunda fase de prática, familiaridade e treino dos 
sujeitos com o instrumento e, finalmente, uma fase de testagem constituída propriamente da aplicação e avaliação do teste proposto. Todos os quatro testes apresentaram a opção de poder-se realizar novamente a fase de prática antes de realizar-se a fase de testagem, bastando a criança apertar a tecla 1 para tal procedimento. Caso a criança estivesse pronta para realizar a fase de testagem e dar início ao teste, bastava apertar a tecla espaço. Os testes que apresentam respostas da criança participante por meio do teclado apresentam pontuação automática, enquanto os testes com respostas verbais da criança participante devem ser contabilizados manualmente.

\subsection{Executivo central}

Apresentaremos primeiramente os testes referentes à avaliação do componente executivo central do sistema de memória de trabalho, sendo eles: frases relembradas e dígitos ao contrário. 0 objetivo desses testes é avaliar a capacidade de armazenagem e processamento da informação de curto prazo de forma simultânea por meio de informações linguísticas.

\subsubsection{Frases relembradas}

O teste frases relembradas consiste na apresentação de grupos de sentenças por intermédio auditivo. Esse teste é composto por 84 sentenças organizadas em grupos. A criança é solicitada a escutar uma sentença, informar se essa sentença é verdadeira ou falsa de acordo com as situações reais no mundo e reter a última palavra de cada sentença para que, em seguida, ela possa ser memorizada e verbalizada pela criança.

a. Fase de aprendizagem e fase de prática Inicialmente, na fase de aprendizagem a criança é solicitada a ouvir uma sentença e dizer se esta é verdadeira ou falsa de acordo com o contexto de realidade no mundo. Em seguida, uma tela é apresentada para instruir a criança a ouvir a sentença novamente e memorizar a última palavra dessa mesma sentença, ao visualizar o ponto de interrogação presente na tela do teste.

Para a fase da aprendizagem, a criança é solicitada a ouvir novamente a mesma frase, dizer se esta é verdadeira ou falsa e memorizar a última palavra de cada sentença escutada. A prática é realizada com seis estímulos para que as crianças se habituem ao procedimento do teste. Destaca-se que o que está sendo efetivamente mensurado neste teste é a capacidade de retenção de itens na memória de trabalho e o processamento linguístico simultâneo, ou seja, quantos itens verbais as crianças conseguem armazenar na memória de trabalho concomitantemente com a realização de outra atividade de processamento ao mesmo tempo. Assim, pode-se dizer que a avaliação da sentença em verdadeira ou falsa acessa o processamento linguístico e a retenção da última palavra ativa o componente de armazenamento respectivamente.

b. Fase de testagem

O primeiro grupo de sentenças na fase de testagem contém quatro sentenças, que são apresentadas uma por vez. Ao final da apresentação de uma sentença, pergunta-se à criança se a sentença é verdadeira ou falsa de acordo com o contexto de mundo real. A resposta da criança é registrada no computador pressionando 1 para verdadeiro e 2 para falso. Em seguida, solicita-se à criança que informe a última palavra daquela sentença. Assim que a resposta é verbalizada, pressiona-se a tecla espaço para a próxima sentença desse grupo.

Esse procedimento é repetido até que as oito sentenças em grupos, sejam apresentadas. Para todos esses grupos de sentenças, o mesmo procedimento é seguido, ao final da última sentença de cada grupo a criança é solicitada a verbalizar a palavra final de cada sentença. Abaixoencontram-se exemplos de atétrêssentenças.

(1) Os cachorros têm quatro patas. (verdadeiro $X$ falso?)

Última palavra da sentença:patas. 
(2) As borboletas comem macarrão. (verdadeiro X falso?)

Os peixes moram no mar. (verdadeiro $\mathrm{X}$ falso?) Últimas palavras das sentenças:macarrão e mar.

(3) No verão, faz frio. (verdadeiro $X$ falso?)

O leite é vermelho. (verdadeiro $X$ falso?)

O ouro é dourado. (verdadeiro $X$ falso?)

Últimas palavras das sentenças:frio, vermelho e dourado.

As sentenças reais e não reais são formadas por uma estrutura simples com sujeito, verbo e complementos verbais, adjuntos adverbiais e predicado nominal. Salienta-se que durante a apresentação da sentença na modalidade auditiva, simultaneamente uma cruz de fixação é apresentada no centro da tela do teste.

O critério de pontuação estabelecido para o teste frases relembradas é de acordo com o número de palavras finais das sentenças, que apesar de estarem fora de ordem, são memorizadas corretamente de acordo com o grupo de sentenças apresentadas. Por exemplo, a criança é capaz de armazenar corretamente a última palavra de três sentenças, sendo assim, a pontuação dessa criança é correspondente a três pontos. Quando a criança não é mais capaz de memorizar as palavras corretamente depois da segunda tentativa, o teste é encerrado. A pontuação equivale de zero a seis pontos, conforme o grupo correspondente de palavras alvo acertadas do grupo de sentenças. A aplicação desse teste durou em média 15 minutos para cada criança participante. A seguinte arquitetura de apresentação dos estímulos foi seguida: 1) primeira tela apresentando o ponto de fixação com a apresentação da frase de forma auditiva, 2) segunda tela com o momento onde a criança deveria verbalizar se a frase era verdadeira ou falsa, 3) a terceira tela descreve o número de estímulos que eram apresentados antes da criança verbalizar as últimas palavras de cada sentença e 4) quarta tela representando o momento em que a criança deveria verbalizar a última palavra de cada sentença, conforme a Figura 1.

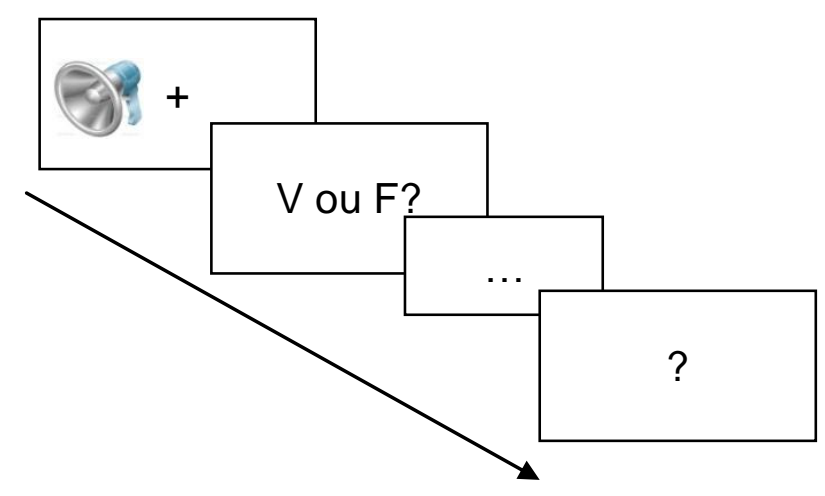

Figura 1 - Arquitetura de apresentação dos estímulos, onde a primeira tela é um ponto de fixação simultâneo a frase estímulo, a segunda tela é a apresentação do estímulo onde o sujeito deve realizar uma escolha, a terceira tela representa o numero de estímulos consecutivos que podem ser apresentados em sequência e a quarta tela o momento onde o sujeito deve produzir as palavras armazenadas.

\subsubsection{Dígitos ao contrário}

O teste dígitos ao contrário tem o mesmo objetivo que o teste frases relembradas, entretanto, esse teste apresenta menos demanda linguística em seu procedimento. O teste consiste na apresentação de grupos de dígitos compostos pelos numerais de um a nove, apresentados por intermédio de estímulos auditivos. Os grupos de dígitos são compostos por 84 gravações contendo de dois a seis dígitos distribuídos em sequência até a mudança para a próxima sequência que aumenta gradativamente. A tarefa da criança participante era ouvir a sequência de dígitos e colocá-la em ordem contrária.

a. Fase de aprendizagem e fase de prática

Nessa fase, a criança é apresentada ao teste com uma tela contendo a seguinte frase: "Você vai escutar uma sequência de dois números, preste atenção e coloque esses números em ordem contrária". Para começar, aperte a tecla espaço. Enquanto a criança escuta a sequência de dois dígitos, uma tela contendo um ponto de fixação permanece na tela do computador, quando essa sequência é finalizada, uma tela contendo um ponto de interrogação, indica que a criança dever verbalizar a resposta, conforme Figura 1. Após a compreensão 
do procedimento a ser feito, a criança pode praticar o teste com mais duas sequências de dois dígitos e, em seguida realizar o teste com a sequência de três dígitos. Ao começar a sequência de três dígitos, a criança escuta um aviso por intermédio de uma gravação de áudio dizendo: "Quando você escutar os três números, lembre-se de dizer o último número, depois o do meio e em seguida o primeiro número".

\section{b. Fase de testagem}

Após a fase de prática, a criança ouve o primeiro grupo de sequência de dígitos e como é orientada na fase de prática, após escutar a sequência de dígitos, é solicitada a colocá-los em ordem contrária. A criança escuta quatro vezes diferentes sequências contendo dois dígitos, até passar para a sequência de três dígitos. Antes de iniciar a próxima sequência, a criança visualiza uma tela avisando que o próximo grupo será apresentado. O mesmo procedimento é realizado até a apresentação do grupo que contém seis dígitos. A seguir, consta o exemplo dos estímulos utilizados no teste dígitos ao contrário.

(1) 5,9

Ordem contrária: 9,5

(2) $3,8,4$

Ordem contrária: 4, 8, 3

(3) $6,1,7,2$

Ordem contrária: 2, 7, 1, 6

É importante enfatizar que, assim como no teste frases relembradas apenas as gravações de áudio são escutadas contendo a sequências dos estímulos, sem nenhum estímulo visual presente em tela, apenas o ponto de fixação. Os dígitos são selecionados para aparecerem em ordem distante da sua ordem canônica para evitar a facilitação do teste. Os estímulos de dígitos foram gravados e apresentados com intervalo de 1000 ms entre si.

O critério de pontuação estabelecido para o teste dígitos ao contrário está de acordo com o número de acertos de sequências de dígitos verbalizados pela criança que estão em ordem contrária, respeitando sua ordem. Por exemplo, se a criança consegue colocar o grupo que contém três estímulos de dígitos na ordem contrária corretamente, a pontuação dessa criança corresponde a três pontos. Quando a criança não é mais capaz de verbalizar corretamente a sequência de dígitos em ordem contrária, após errar na segunda tentativa, o teste é encerrado. A pontuação para esse teste equivale de zero a seis pontos e a sua aplicação durou em média treze minutos para cada criança participante.

\subsection{Alça fonológica}

O componente alça fonológica é avaliado por meio da memória fonológica, que por sua vez, enfatiza a alça fonológica do modelo de representação mental do sistema de memória de trabalho (BADDELEY; HITCH, 1974) apresentado anteriormente. Os testes recuperação da listade palavras e palavras inexistentes têm como objetivo avaliar a capacidade de armazenamento da informação verbal de curto prazo, sendo que o primeiro teste avalia a capacidade de armazenagem de palavras existentes e o segundo teste avalia a armazenagem de palavras não existentes.

\subsubsection{Recuperação da lista de palavras}

O teste recuperação da lista de palavras consiste na apresentação de grupos de palavras reais apresentados auditivamente. Esses grupos são constituídos de uma a seis palavras e contêm quatro apresentações em cada conjunto, ou seja, a criança escuta uma sequência de cada vez, e, depois disso, escuta mais três vezes outras palavras em sequências diferentes de cada conjunto. A criança é solicitada a escutar a sequência de palavras de um determinado grupo e em seguida verbalizar as palavras na mesma sequência que é apresentada.

a. Fase de aprendizagem e fase de prática

$\mathrm{Na}$ fase de aprendizagem explica-se para a criança como será o procedimento do teste e, em seguida, uma tela inicial aparece para dar continuidade à explicação. Após a criança realizar a 
aprendizagem com uma palavra, outra tela é apresentada com as instruções da fase de aprendizagem com duas palavras e assim por diante.

\section{b. Fase de testagem}

Para iniciar o teste, a tarefa a ser realizada é explicada novamente à criança. Enquanto a criança participante escuta a sequência de palavras, uma cruz de fixação permanece na tela do teste. Após o início do procedimento, depois de escutar a sequência de palavras, a tecla espaço é apertada e outra tela contendo um ponto de interrogação aparece na tela do teste, semelhante a da Figura 1, indicando que a criança participante deve verbalizar as palavras que consegue armazenar, preferencialmente na mesma ordem que as escutou.

No decorrer desse teste, após o aumento do número de itens nos grupos de palavras, uma tela aparece indicando quantas palavras são escutadas pela criança. Ao finalizar o grupo de duas palavras, outra tela aparece indicando que será iniciado o grupo de três palavras. Após apertar a tecla espaço, o teste prossegue. O mesmo procedimento é seguido cada vez que é aumentado o número de palavras apresentadas em cada grupo até a conclusão do teste. O número de palavras aumenta gradativamente após a finalização da sequência anterior até atingir o grupo de seis palavras. As palavras utilizadas no teste recuperação da lista de palavras estão distribuídas na Tabela 1.
As palavras utilizadas para a construção desse teste foram monossílabos e dissílabos do português brasileiro. $\mathrm{Na}$ programação do teste, depois da apresentação de cinco palavras em diante, as palavras dissílabas foram reduzidas devido ao aumento do número de palavras monossílabas. Esse procedimento foi importante para evitar a sobrecarga de palavras maiores (dissílabas) no sistema de armazenagem. Também foram escolhidas palavras com diferenças fonológicas no português brasileiro no início das palavras a fim de evitar confusão com sons semelhantes apresentadas anteriormente no mesmo grupo de palavras. Tais critérios foram estabelecidos de acordo com a bateria de testes original Memory Test Battery For Children.

Nesse teste, a criança pontua se acertar as palavras apresentadas na mesma ordem em que são exibidas. Quando as crianças não acertam as palavras em sua ordem depois da segunda tentativa, o teste é encerrado. A pontuação estabelecida foi de zero a seis pontos, conforme o grupo de palavras acertadas em sequência. A execução desse teste durou em média dez minutos para cada criança participante.

Tabela 1 - Lista de estímulos do teste recuperação da lista de palavras.

\begin{tabular}{|c|c|c|c|c|c|}
\hline Uma palavra & Duaspalavras & Trêspalavras & Quatropalavras & Cinco palavras & SeisPalavras \\
\hline tempo & $\begin{array}{l}\text { boca } \\
\text { casa }\end{array}$ & $\begin{array}{c}\text { sino } \\
\text { terra } \\
\text { mesa }\end{array}$ & $\begin{array}{c}\text { noite } \\
\text { lobo } \\
\text { fruta } \\
\text { pé }\end{array}$ & $\begin{array}{c}\text { chave } \\
\text { leite } \\
\text { avô } \\
\text { uva } \\
\text { cruz }\end{array}$ & $\begin{array}{c}\text { manga } \\
\text { ele } \\
\text { chá } \\
\text { mil } \\
\text { cor } \\
\text { lei }\end{array}$ \\
\hline língua & $\begin{array}{l}\text { planta } \\
\text { sala }\end{array}$ & $\begin{array}{l}\text { carro } \\
\text { chão } \\
\text { gato }\end{array}$ & $\begin{array}{l}\text { lua } \\
\text { quarto } \\
\text { pote } \\
\text { fato }\end{array}$ & $\begin{array}{l}\text { vaca } \\
\text { tatu } \\
\text { deus } \\
\text { fio } \\
\text { pá }\end{array}$ & $\begin{array}{c}\text { pera } \\
\text { tio } \\
\text { nu } \\
\text { grão } \\
\text { mãe } \\
\text { gel } \\
\end{array}$ \\
\hline olho & $\begin{array}{c}\text { pé } \\
\text { zebra }\end{array}$ & $\begin{array}{c}\text { mão } \\
\text { bebê } \\
\text { luz }\end{array}$ & $\begin{array}{l}\text { jardim } \\
\text { anel } \\
\text { chuva } \\
\text { rei }\end{array}$ & $\begin{array}{l}\text { folha } \\
\text { doce } \\
\text { pão } \\
\text { céu } \\
\text { boi }\end{array}$ & $\begin{array}{l}\text { dois } \\
\text { nó } \\
\text { bom } \\
\text { mel } \\
\text { gol } \\
\text { pai }\end{array}$ \\
\hline sinal & $\begin{array}{l}\text { muito } \\
\text { peixe }\end{array}$ & $\begin{array}{c}\text { dia } \\
\text { chapéu } \\
\text { sol }\end{array}$ & $\begin{array}{l}\text { dente } \\
\text { tem } \\
\text { passo } \\
\text { ouro }\end{array}$ & $\begin{array}{l}\text { café } \\
\text { herói } \\
\text { mar } \\
\text { eu } \\
\text { sal }\end{array}$ & $\begin{array}{l}\text { claro } \\
\text { era } \\
\text { quem } \\
\text { lá } \\
\text { pó } \\
\text { mês } \\
\end{array}$ \\
\hline
\end{tabular}




\subsubsection{Palavrasinexistentes}

Este teste é composto por um grupo de pseudopalavras apresentadas em uma sequência de cinco itens. As pseudopalavras foram compostas por no mínimo uma e no máximo seis sílabas que eram aumentadas gradativamente. A criança é solicitada a escutar a pseudopalavra e em seguida verbalizá-la conforme a escutou. Destaca-se que as pseudopalavras são um excelente meio para acessarse a compreensão e produção fonológica sem conteúdo semântico.

a. Fase de aprendizagem e prática

O mesmo procedimento utilizado no teste recuperação da lista de palavras foi seguido na fase de aprendizagem e prática desse teste. No primeiro momento, a criança recebe a instrução da tarefa que deve ser realizada por intermédio de uma tela do teste e com a explicação do experimentador. A criança é avisada que irá escutar palavras que não existem em nossa língua, mas que devem ser verbalizadas conforme as havia escutado. A fase de aprendizagem foi constituída de uma a três pseudopalvras para a familiarização da criança com o teste, enquanto na fase de prática, a criança pode treinar com palavras maiores.

\section{b. Fase de testagem}

Depois da compreensão da tarefa a ser realizada, a fase de testagem começa. Enquanto a criança escuta as pseudopalavras, uma cruz de fixação permanece na tela do teste e após a finalização dos estímulos auditivos, uma tela contendo um ponto de interrogação, conforme na Figura 1, indica que a criança deve verbalizar a resposta.

Após a apresentação da primeira sequência de pseudopalavras, a segunda sequência é apresentada após o participante apertar a tecla espaço. Essa mesma ordem é seguida para as outras sequências de pseudopalavras presentes nesse teste. As pseudopalavras utilizadas no teste palavras inexistentes foram propostas por Kessler (1997). Na

Tabela 2, segue a apresentação das pseudopalavras. Cada estímulo teve em média um segundo até a apresentação do próximo estímulo.
Tabela 2 - Lista de pseudopalavras utilizadas no teste palavras inexistentes (KESSLER, 1997).

\begin{tabular}{cccccc}
\hline $\begin{array}{c}\text { Uma } \\
\text { sílaba }\end{array}$ & $\begin{array}{c}\text { Duassíla } \\
\text { bas }\end{array}$ & $\begin{array}{c}\text { Trêssíla } \\
\text { bas }\end{array}$ & $\begin{array}{c}\text { Quatrosí } \\
\text { labas }\end{array}$ & $\begin{array}{c}\text { Cinco } \\
\text { sílabas }\end{array}$ & $\begin{array}{c}\text { Seis } \\
\text { sílabas }\end{array}$ \\
\hline bó & dalu & quentagi & palifemo & dojabefari & femurituzoli \\
lum & leca & belsifi & romutega & ranocidomi & alcabinteroca \\
rau & nusa & tonasso & pefisuni & zalivemafu & zovibescofari \\
pin & bunfe & lanasi & morinatij & gocipobilo & gerobinfoquemi \\
fe & queuci & gamalo & alopurti & agucarife & chedizatocaro \\
\hline
\end{tabular}

A criança pontua no teste quando acerta a verbalização correta das pseudopalavras apresentadas. Quando a criança para de acertar as pseudopalavras de um determinado grupo depois da segunda tentativa, o teste é encerrado. Os acertos são contabilizados de zero a seis pontos, conforme o grupo de pseudopalavras acertadas. A execução desse teste durou em média oito minutos para cada criança.

Para verificar os resultados nos quatro testes que avaliam o sistema de memória de trabalho que foram construídos e adaptados para o português brasileiro, realizamos a comparação dos resultados e o tratamento dos dados do grupo controle e do grupo experimental por meio do teste ANOVA, com nível de significância das análises estatísticas de 0,05 (5\%).

\section{Resultados}

Iniciaremos a análise estatística pelos dois testes que avaliam o componente executivo central, sendo esses os testes frases relembradas e dígitos ao contrário. A Tabela 3 , a seguir, mostra a comparação para os dois grupos referentes aos dois testes.

Tabela 3 - Comparação entre os grupos para os testes de executivo central.

\begin{tabular}{ccccc}
\hline $\begin{array}{c}\text { Memória de } \\
\text { trabalho }\end{array}$ & \multicolumn{2}{c}{$\begin{array}{c}\text { Frasesrelembradas } \\
\text { Experimental }\end{array}$} & Controle & \multicolumn{2}{c}{ Dígitosaocontrário } \\
& Experimental & Controle \\
\hline Média & 2,47 & 3,53 & 1,98 & 2,68 \\
Mediana & 3 & 4 & 2 & 3 \\
DesvioPadrão & 0,64 & 0,52 & 0,33 & 0,45 \\
Min & 1 & 3 & 1 & 3 \\
Max & 3 & 4 & 3 & 4 \\
N & 15 & 15 & 15 & 15 \\
\hline
\end{tabular}


De acordo com a Tabela 3, ao se comparar a média entre os dois grupos no teste frases relembradas, o grupo experimental apresenta desempenho inferior de 2,47 quando comparada a do grupo controle 3,53. A diferença entre os dois grupos é estatisticamente significante pelo resultado do teste ANOVA $(F(1,29)=25,24, p<0,001)$. O mesmo resultado pode ser observado na Tabela 3 para 0 teste dígitos aocontrário, em que o grupo experimental apresenta desempenho de 1,98 quando comparada ao grupo controle 2,68. A diferença entre os dois grupos éestatisticamente significante pelo resultado do teste ANOVA $(F(1,29)=18,22, p<$ 0,001).

A próxima análise estatística é referente ao desempenho dos dois grupos nos testes que avaliaram a alça fonológica, sendo esses os testes recuperação da listade palavras e palavras inexistentes. A Tabela 4 a seguir, mostra a comparação para os dois grupos referentes aos dois testes.

Tabela 4 - Comparação entre os grupos para os testes de alça fonológica.

\begin{tabular}{ccccc}
\hline $\begin{array}{c}\text { Memória de } \\
\text { trabalho }\end{array}$ & \multicolumn{2}{c}{$\begin{array}{c}\text { Recuperaçãolista de } \\
\text { palavras }\end{array}$} & \multicolumn{2}{c}{ Palavrasinexistentes } \\
& Experimental & Controle & Experimental & Controle \\
\hline Média & 3,67 & 4,60 & 4,47 & 5,60 \\
Mediana & 4 & 5 & 4 & 6 \\
DesvioPadrão & 0,72 & 0,63 & 0,52 & 0,63 \\
Min & 2 & 4 & 4 & 4 \\
Max & 5 & 6 & 5 & 6 \\
N & 15 & 15 & 15 & 15 \\
\hline
\end{tabular}

No que diz respeito ao teste recuperação da lista de palavras, a Tabela 4 apresenta a média de desempenho para o grupo experimental 3,67 menor do que a média para o grupo controle 4,60. O teste ANOVA para 0 desempenho das crianças participantes em relação ao teste recuperação da lista de palavras demonstrou que houve diferenças estatisticamente significantes entre os dois grupos $(F(1,29)=14,14, p<0,001)$. Como apresentado na Tabela 4, no teste palavras inexistentes os dois grupos apresentaram médias de acerto diferentes, com valores menores para o para o grupo experimental 4,47 do que para o grupo controle 5,60. $\mathrm{O}$ teste ANOVA demonstrou que houve diferenças estatisticamente significantes entre os dois grupos $(\mathrm{F}(1,29)=28,90, \mathrm{p}<0,001)$ para 0 teste palavras inexistentes.

\section{Discussão}

O estudo piloto apresentado no presente artigo revelou que as crianças que participaram do presente estudo apresentaram boa compreensão da tarefa que deveria ser realizada em cada teste. Durante a fase do estudo piloto, nenhuma criança desistiu de realizar nenhum dos testes propostos, sendo assim, infere-se que todo o material linguístico cuidadosamente separado e organizado como estímulos em português brasileiro estavam apropriados ao vocabulário infantil.

Os resultados distribuídos na Tabela 3 e na Tabela 4 mostram que o grupo experimental apresentou desempenho significativamente inferior em todos os testes de memória de trabalho quando comparado ao grupo controle. Esses resultados sugerem que os quatro testes adaptados no presente estudo baseados na adaptação da bateria de testes WorkingMemory Test for Children(PICKERING; GATHERCOLE, 2001) obtiveram um excelente desempenho na avaliação da memória de trabalho em crianças, já que foi capaz de diferenciar o desempenho entre os grupos. Conforme os resultados do estudo piloto, os testes aplicados no presente estudo aparentam serem instrumentos linguísticos sensíveis e apropriados para detectar dificuldades relacionadas ao processamento da memória de trabalho em crianças, tanto no nível linguístico como não linguístico. Mais do que isto, tendo-se a bateria de testes consolidados por meio deste estudo piloto para pesquisas sobre a memória de trabalho em crianças, o presente estudo corrobora com as relações diretas entre a memória de trabalho e as funções cognitivas de aprendizagem e processamento da linguagem.

Sendo assim, a Bateria de Testes de Memória de Trabalho para Crianças (BTMTC) apresentou os resultados esperados, objetivos e claros sobre a avaliação das capacidades de processamento e de armazenamento do sistema de memória de trabalho.

A partir dos dados obtidos na presente pesquisa 
piloto com crianças normais e crianças com dificuldades escolares devido a algumas comorbidades, pode-se identificarquais processos linguísticos no sistema de memória de trabalho foram mais afetados a fim de poder-se preparar uma intervenção, e melhor, compreender estas características de uma forma geral. Com o desenvolvimento e o estabelecimento dessa bateria de testes de memória, pode-se pensar em um instrumento de diagnóstico para dificuldades no processamento do sistema de memória de trabalho, que por sua vez, podem comprometer outros testes cognitivos complexos.

Por ser tratar de um estudo piloto para testar os testes propostos que avaliam o sistema de memória de trabalho, não podemos comparar nossos achados com outros presentes na literatura, mas apenas em um nível interlinguístico (ESTIVALET, 2010) com estudos internacionais que utilizaram a WorkingMemory Test for Children, o instrumento que nos deu base para adaptação dos testes propostos.

Pesquisadores investigaram o sistema de memória de trabalho de crianças anglófonas com distúrbio específico de linguagem (DEL) por meio da WorkingMemory Test for Children. Essas crianças formaram um grupo experimental e foram comparadas a um grupo de crianças com desenvolvimento típico, sendo esse o grupo controle. Os resultados desse estudo apresentaram dados significativos em relação às diferenças de memória de trabalho nos diferentes componentes abordados nessa pesquisa (LUM; CONTI-RAMSDEN; PAGE; ULLMAN, 2012). O estudo utilizou testes que avaliaram o componente executivo central e a alça fonológica da memória de trabalho e encontrou desempenho inferior nesses testes para as crianças com DEL quando comparadas ao grupo controle. Nesse estudo, a WorkingMemory Test for Children foi capaz de diferenciar os resultados entre um grupo controle e um grupo experimental. A partir de nossos resultados, podemos considerar o mesmo sucesso da adaptação dos quatro testes adaptados e apresentados no presente artigo. Os resultados de Lumet al., (2012) assemelham-se diretamente aos nossos resultados apresentados na Tabela 3 e na Tabela 4. Os testes de memória de trabalho adaptados para o português brasileiro apresentaram distintos na comparação entre os dois grupos que constituíram a amostra, onde foi possível evidenciar diferenças no desempenho da memória de trabalho, com pontuações inferiores nas crianças do grupo experimental em relação à armazenagem e processamento da informação de curto prazo simultaneamente a armazenagem da informação verbal de curto prazo, quando comparadas ao grupo controle.

A fim de testar a eficácia de uma proposta de intervenção com base no sistema de memória de trabalho, um estudo aplicou a WorkingMemory Test for Children em um grupo de crianças que foram afetadas pelo distúrbio do espectro fetal alcoólico, que consiste em um conjunto de más formações em crianças que as mães consumiam álcool durante a gravidez, causando assim, dificuldades intelectuais, comportamentais e cognitivas (LOOMES; RASMUSSEN; PEI; MANJI; ANDREW, 2008). Antes do processo de intervenção, os pesquisadores aplicaram o teste que envolvia a capacidade de armazenagem e processamento da informação simultânea utilizando dígitos, o teste que deu base para o teste dígitos ao contrário aplicado no presente estudo piloto. As crianças apresentaram desempenho superior nesse teste após a intervenção proposta pelos autores, o que significa que o teste foi sensível para detectar o desempenho inferior pré-treinamento e 0 desempenho superior pós-treinamento individualmente. $\mathrm{O}$ objetivo desse estudo foi realizar uma proposta de intervenção na capacidade de memória de trabalho, mesmo assim os resultados pré- e pós-treinamento se assemelham aos resultados encontrados na Tabela 3, quando comparamos o desempenho do grupo controle e do grupo experimental no teste dígitos ao contrário, em que os grupos apresentaram resultados diferentes e o instrumento foi sensível para captar essas diferenças.

Para investigar a relação entre o sistema de memória de trabalho e habilidades de leitura e cálculo matemático, assim como outras habilidades como 
nível de inteligência, memória de curto prazo e consciência fonológica, um estudo utilizou como um dos instrumentos de pesquisa os testes da WorkingMermory Test for Childrenem 46 crianças na faixa etária entre seis e 11 anos que apresentavam dificuldades relacionadas à leitura (GATHERCOLE; ALLOWAY; WILLIS; ADAMS, 2006). Os testes utilizados correspondiam à avaliação do armazenamento e processamento da informação verbal de forma simultânea da bateria WorkingMermory Test for Children, se mostrando sensível para detectar as dificuldades encontradas pelas crianças participantes do que diz respeito ao sistema de memória de trabalho. Os achados desse estudo sugerem que as habilidades de memória de trabalho representam um importante construto para a aquisição de habilidades e conhecimentos em leitura e matemática. Os resultados encontrados nesse estudo assemelham-se aos nossos resultados da

Tabela 3 e Tabela 4, evidenciando a sensibilidade dos testes da BTMTC adaptados para o português brasileiro. Portanto, assim como os autores desse estudo, acreditamos na importância do desenvolvimento de testes que possam avaliar as habilidades complexas de memória para auxiliar no diagnóstico e reabilitação de crianças que apresentam dificuldades escolares.

\section{Conclusão}

A Bateria de Testes de Memória de Trabalho para Crianças(BTMTC) foi desenvolvida de forma satisfatória e eficaz, pois apresentou os resultados esperados: uma bateria de testes de memória de trabalho para crianças que avalia a capacidade das diferentes estruturas do sistema de memória de trabalho, assim como a especificidades desse sistema de memória em relação à informação linguística.

Os resultados do estudo piloto em relação aos quatro testes de memória de trabalho que foram adaptados e baseados na bateria de testes WorkingMemory Test for Children, sugerem que esses instrumentos são sensíveis, coerentes e eficazes para detectar dificuldades no processamento da memória de trabalho em crianças, a partir dos resultados que obtivemos quando comparamos 0 grupo experimental ao grupo controle. Estudos futuros com um número maior de crianças e de diferentes faixas etárias nos fornecerão mais indícios nos testes que aplicamos na presente pesquisa e poderão fornecer evidências sobre o desenvolvimento do sistema de memória de trabalho infantil. Esses estudos também nos permitirão obter um parâmetro mais específico para considerar os padrões de normalidade em relação aos testes propostos de acordo com a faixa etária das crianças. Os testes propostos também podem ser utilizados para estudar a relação da memória de trabalho com funções cognitivas complexas em crianças.

\section{Referências}

ALLOWAY, T. P.; GATHERCOLE, S. E.; ADAMS, A. M.; WILLIS, C. Working memory abilities in children with special educational needs. Education \& Child Psychology, 22(2), p. 56-67. 2005.

BADDELEY, A. D.; HITCH, G. J. Working Memory. In: BOWER, G. H. Thepsychology of learning and motivation: Advances in research and theory. New York: Academic Press, 1974. p. 47-89.

BADDELEY, A. D. The episodic buffer: A new component in working memory? Trends in Cognitive Science, 4(11), p. 417-423. 2000.

DE BENI, R.; BORELLA, E.; CARRETI, B. Reading comprehension in aging: The role of working memory and metacomprehension. AgingNeuropsychologyandCognition 14(8), p. 189212. 2007.

ESTIVALET, G. L. A memória de trabalho e a produção em $L 2$ do francês e do inglês por falantes do português como L1. I Simpósio Internacional do Núcleo Interdisciplinar de Estudos da Linguagem. Recife/PE: Anais eletrônicos do I SINIEL, agosto, 2010.

GATHERCOLE, S. E.; ALLOWAY, T. P.; WILLIS, C.; ADAMS, A. M. Working memory in children with reading disabilities.Journalof Experimental ChildPsychology, 93(3), p. 265-291. 2006.

GINDRI, G.; KESKE-SOARES, M.; MOTA, H. B. Memória de trabalho, consciência fonológica e hipótese de escrita. Pró-Fono Rev AtualCient. 19(3), p. 313-22. 2007. 
LOOMES, C.; RASMUSSEN, C.; PEI, J.; MANJI, S.; ANDREW, G.The effect of rehearsal training on working memory span of children with fetal alcohol spectrum disorder.Res in develop Disabi. 29(7), p. 113-124, 2008.

LUM, J. A. G.; CONTI-RAMSDEN, G.; PAGE, D. ; ULLMAN, M.T. Working, declarative and procedural memory in specific language impairment. Cortex 48(9), p. 1138-1154. 2012.

MOOJEN, S.; LAMPRECHT, R.; SANTOS, R. M.; FREITAS, G. M.; BRODACZ, R.; SIQUEIRA, M.; COSTA, A. C.; GUARDA, E. CONFIAS: Consciência fonológica: Instrumento de Avaliação Sequencial. São Paulo: Casa do Psicólogo, 2011.

MOSER, D. D.; FRIDRIKSSON, J.; HEALY E. W. Sentence comprehension and general working memory.Clin Linguist e Phonet. 21(9), p. 147-156. 2007.

MUSIEK, F.E et al. The GIN (GAPS-IN-NOISE) Test performance in subjects with confirmed central auditory nervous system involvement. Hear and Hearing. 26 (8), p. 608-18.2005.

PICKERING, S. J.; GATHERCOLE, S. E. Working Memory Test Battery for Children.Psychological Corporation. UK, 2001.

PINHEIRO, A. M. V. Leitura e escrita: uma abordagem cognitiva. $1^{\underline{a}}$ ed. Campinas: Editorial Psy. 1994.

RODRIGUES, C. Contribuições da memória de trabalho para o processamento da linguagem: Evidências experimentais e clínicas. WorkPap em Linguíst. 5(5), p. 124-144. 2001.

SANTOS, M.F.C, PEREIRA, L.D. Escuta com dígitos. In: PEREIRA L.D, SCHOCHAT E. Processamento auditivo central: manual de avaliação. São Paulo: Lovise; 1997. p. 147-50.

SANTOS, M. R.; SIQUEIRA, M. Consciência fonológica e memória. Rev FonoAtual. 5(20), p. 4853. 2002.

SCHNEIDER, W.; ESCHMAN, A.; ZUCCOLOTTO, A. E-Prime. Psychology SoftwareTools, Inc.Learning Research and Development Center: University of Pittsburgh, 2007.

SCLIAR-CABRAL, L. Guia prático de alfabetização. $1^{\text {a }}$ ed. São Paulo: Contexto, 2003b.

SWANSON, H. L.; JERMAN, O.The influence of working memory on Reading growth in subgroups of children with disabilities. JourofExperimChildPsychol. 96(16), p. 249-283.

ZILLIOTTO, K, N.; KALIL, D,M.; ALMEIDA, C,I,R. PSI em português. In: Pereira, LD, Schochat, E. Processamento auditivo central: Manual de avaliação. São Paulo, Lovise, 1997. p. 113-128. 